\title{
RANCANG BANGUN TRAINER TERINTEGRASI RANGKAIAN PENYEARAH GELOMBANG DAN PENGUAT OP-AMP BERBASIS MIKROKONTROLER ATMEGA 32
}

\author{
Resa Pramudita ${ }^{1}$, Ase Suryana ${ }^{2}$ \\ Program Studi Teknik Elektro ${ }^{1,2}$ \\ Universitas Widyatama \\ Jalan Cikutra no 204A, Kota Bandung \\ $\underline{\text { resa.pramudita@widyatama.ac.id }}^{1}{ }^{1}, \underline{\text { ase.suryana@ widyatama.ac.id }}^{2}$
}

\begin{abstract}
Abstrak
Penyearah setengah gelombang, penyearah gelombang penuh, penguat op-amp inverting, dan penguat op-amp non inverting merupakan materi praktikum elektronika dasar di setiap Jurusan Teknik Elektro. Selama ini praktikum dilaksanakan dengan menyusun rangkaian secara manual menggunakan breaadboard, sehingga membutuhkan waktu yang lama dan tidak efisien. Pada penelitian ini dirancang sebuah trainer dengan modul yang saling terintegrasi. Modul tersebut terdiri dari modul penyearah gelombang, modul penguat transistor, modul penguat op-amp, dan gerbang logika. Trainer ini didesain berbasis mikrokontroler atmega 32 yang berfungsi untuk memilih modul, menampikan pengerjaan modul, dan program gerbang logika dasar. Metode yang digunakan pada penelitian ini adalah eksperimen dan simulasi. Dari hasil pengujian, modul penyearah setengah gelombang dan penyearah gelombang penuh memberikan respon sesuai dengan simulasi kondisi ideal. Sementara hasil pengujian modul penguat opamp inverting dan penguat non inverting, menunjukkan kedua modul dapat berfungsi sesuai dengan teori dan simulasi. Jadi dapat disimpulkan trainer ini dapat digunakan untuk pembelajaran praktikum..
\end{abstract}

Kata kunci:

Trainer, Penyearah gelombang, Penguat op-amp inverting, Penguat op-amp non inverting, Mikrokontroler

\begin{abstract}
Half-wave rectifier, full-wave rectifier, inverting opamp amplifier, and non-inverting op-amp amplifier are basic electronic practicum material in each Electrical Engineering Department. During this practicum is carried out by arranging the circuit manually using breaadboard, so it requires a long time and is inefficient. In this study a trainer with integrated modules was designed. The module consists of a wave rectifier module, transistor amplifier module, op-amp amplifier module, and logic gate. This trainer is designed based on the ATmega 32 microcontroller which functions to select modules, display module workmanship, and basic logic gate programs. The method used in this research is experiment and simulation. From the test results, the half-wave rectifier and full-wave rectifier modules respond according to the simulation of ideal conditions. While the results of testing the inverting amplifier and non-inverting amplifier, show both modules can function in accordance with theory and simulation. So it can be concluded that this trainer can be used for practical learning.
\end{abstract}

Keywords:

Trainer, Wave rectifier, Inverting op-amp amplifier, Non-inverting op-amp amplifier, Microcontroller 


\section{Pendahuluan}

Faktor-faktor yang mempengaruhi prestasi belajar banyak jenisnya. Salah satu faktor yang mempunyai pengaruh dalam pencapaian hasil belajar adalah media pembelajaran yang digunakan saat proses belajar mengajar [3].

Rangkaian penyearah gelombang dan rangkaian op-amp inverting dan non inverting merupakan salah satu bagian dari sub materi yang dipelajari pada mata kuliah Praktikum Elektronika dasar di setiap jurusan Teknik Elektro. Rangkaian penyearah gelombang sebagai pemahaman dasar dari tegangan ripple pada penyearah biasa digunakan pada rangkaian power supply sebagai pengubah dari arus bolak balik menjadi arus searah . Begitu juga dengan rangkaian penguat inverting dan non inverting sebagai pemahaman dasar penguatan tegangan dan beda phasa biasa digunakan sebagai driver pada rangkaian sensor maupun rangkaian penguat audio.

Pada pelaksanaan praktikum, mahasiswa sering dihadapkan pada kesulitan dalam memahami rangkaian. Mahasiswa dituntut untuk bisa merangkai secara manual pada breadboard dan menganalisa rangkaian. Di setiap laboratorium elektronika untuk membuat rangkaian percobaan masih menggunakan komponen-komponen yang terpisah dari trainer. Kondisi seperti ini dapat menghambat praktikum ketika komponen yang digunakan tidak ada atau sudah rusak.

Dalam pembelajaran op-amp banyak media pembelajaran yang digunakan salah satunya adalah media pembelajaran animasi flash [2], namun media ini dianggap kurang memberi pengalaman nyata pada praktikan dalam memahami rangkaian.

Dalam pembelajaran penyearah gelombang juga banyak media yang dapat digunakan salah satunya menggunakan trainer elektronika dasar yang sudah terintegrasi dalam satu modul [3], penggunaan media ini sudah cukup baik namun belum dilengkapi dengan informasi langkah langkah percobaan yang terhubung ke program lcd mikrokontroller.

Dari permasalahan dan uji observasi tersebut, dirancanglah trainer terintegrasi antar modul, yang terdiri dari modul penyearah gelombang, penguat transistor, op-amp, dan gerbang logika. Trainer ini didesain berbasis mikrokontroler yang dilengkapi
LCD sebagai informasi kepada praktikan untuk mempermudah praktikum.

\section{KAJIAN LITERATUR}

\section{Rangkaian Penyearah Gelombang}

Banyak dari Peralatan elektronika kecil menggunakan sumber tegangan baterai sebagai sumber dayanya, namun banyak juga peralatan yang menggunakan sumber daya AC 220 volt dengan frekuensi $50 \mathrm{~Hz}$. Didalam peralatan tersebut terdapat rangkaian yang sering disebut sebagai adaptor atau penyearah yang mengubah sumber tegangan bolak balik (AC) menjadi tegangan searah (DC). Bagian terpenting dari adaptor adalah berfungsinya diode sebagai penyearah (rectifier), ada dua jenis penyearah menggunakan diode yaitu half wave rectifier dan full wafe rectifier [6]. yang diperlihatkan oleh Gambar.1 dan Gambar.2 berikut

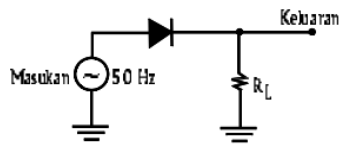

(a)

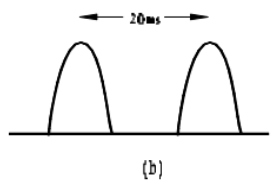

Gambar 1. (a) Rangkaian Penyearah setengah gelombang. (b) Output penyearah gelombang penuh. [6]

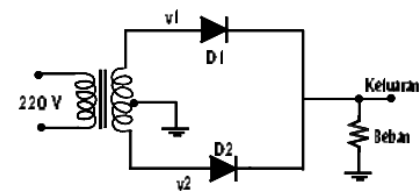

(a)

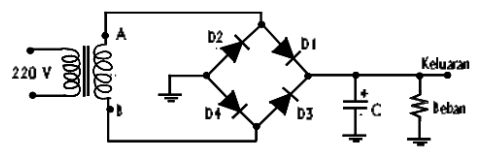

(b)

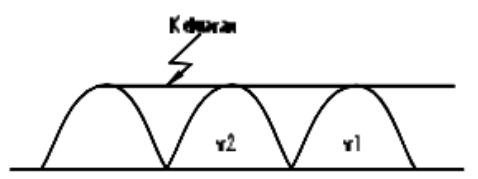

(c)

Gambar 2. (a) Penyearah gelombang penuh 2 dioda, (b) penyearah gelombang penuh jembatan, (c) output penyearah gelombang penuh.[6]

Resa Pramudita, Ase Suryana 
2. Rangkaian Op-Amp Inverting dan Non Inverting

Rangkaian inverting amplifier menggunaka op amp merupakan rangkaian penguat dengan membalikan nilai fasa dengan impedansi masukan sangat rendah. Rangkaian inverting amplifier akan menerima arus atau tegangan dari tranduser sangat kecil dan akan membangkitkan arus atau tegangan yang lebih besar [7]. Rangkaian dasar penguat inverting adalah seperti yang ditunjukkan pada gambar.3

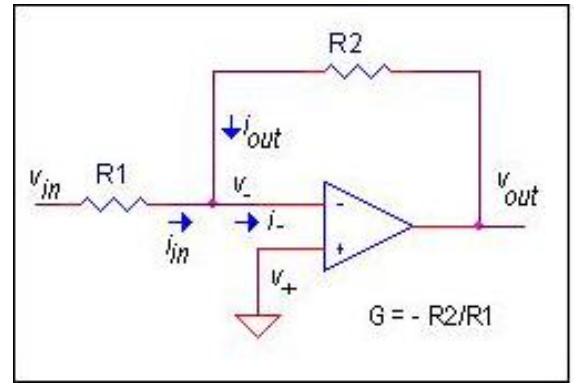

Gambar 3. Rangkaian Inverting amplifier [7]

Diamana nilai tegangan output dari rangkaian ini dapat dihitung menggunakan persamaan berikut :

$V_{\text {out }}=-\frac{R 2}{R 1} x V_{\text {in }}$

Apabila kita ingin nilai output dari tegangan tersebut tidak berbalik fasa maka kita harus menggunakan rangkaian non inverting amplifier. Non inverting amplifier ini memiliki masukan yang dibuat melalui input minus atau input non-inverting. Dengan demikian tegangan keluaran rangkaian ini akan satu fasa dengan tegangan inputnya [7].

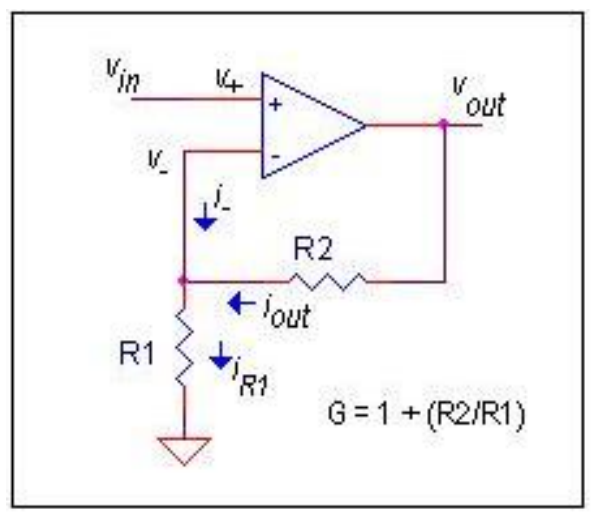

Gambar 4. Rangkaian Non Inverting amplifier [7]
Diamana nilai tegangan output dari rangkaian ini dapat dihitung menggunakan persamaan berikut :

$$
\mathrm{V}_{\text {out }}=\mathrm{V}_{\text {in }}\left(1+\mathrm{R}_{2} / \mathrm{R}_{1}\right)
$$

\section{METODOLOGI}

Pada penelitian ini terdiri dari modul penyearah gelombang dan modul op-amp. Untuk Modul rangkaian penyearah gelombang terdiri dari dua bagian, yaitu:

1. Modul penyearah setengah gelombang,

2. Modul penyearah gelombang penuh, yaitu:

Untuk Modul op-amp terdiri dari dua bagian,

1. Rangkaian penguat inverting,

2. Rangkaian penguat non inverting,

Pada pembahasan ini, gambar yang dikelilingi garis merah adalah modul penyearah gelombang dan penguat op-amp inverting dan non inverting. Gambar dari tampilan dari trainer ini adalah seperti ditunjukan pada Gambar 4 :

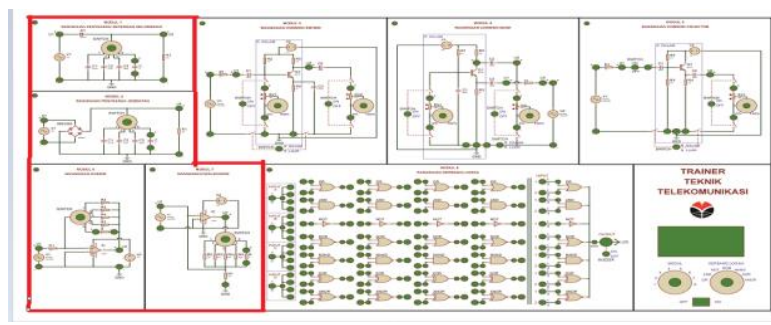

Gambar 4. Tampilan atas trainer teknik telekomunikasi

Pada trainer ini, fungsi dari mikrokontroler adalah sebagai saklar switch untuk memilih modul mana yang akan dipakai untuk praktikum. Jadi pada saat praktikum trainer ini tidak bisa langsung menjalankan semua modul. Hal ini untuk memfokuskan praktikan dalam memahami tiap modul rangkaian.

Metode perancangan dan pembuatan alat yang digunakan adalah metode eksperimen dan simulasi yaitu dengan cara membandingkan hasil pengujian dengan menggunakan software simulasi yang sudah tervalidasi dan perancangan langsung. Langkahlangkah pada perancangan ini terdapat pada gambar flowchart yang ditunjukan pada gambar 5

Resa Pramudita, Ase Suryana

Volume 6, No 1, 15 Desember 2019 


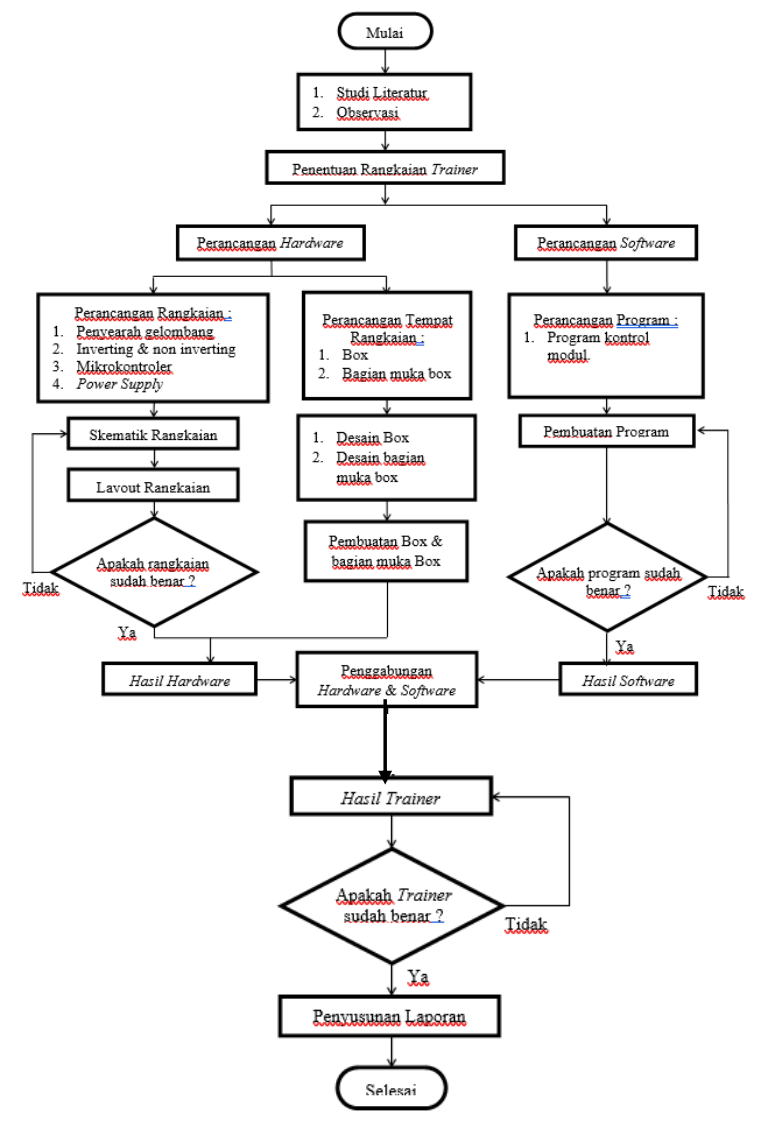

Gambar.5 Flowchart prosedur perancangan alat

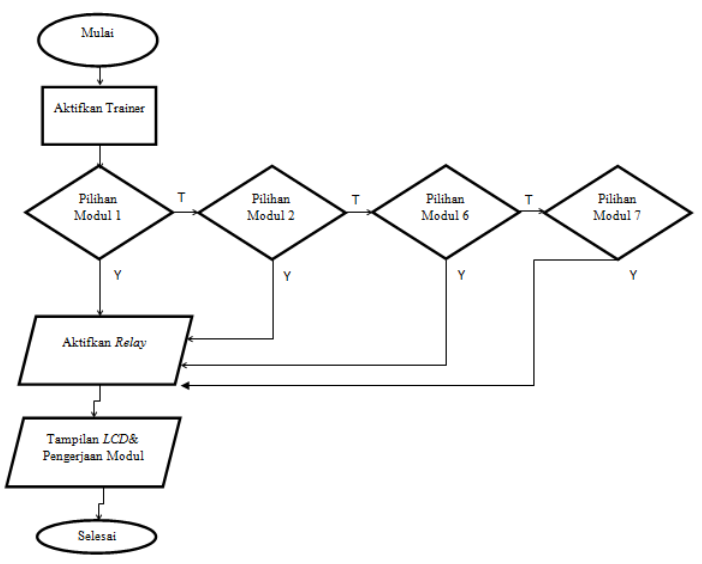

Gambar 6. Blok Diagram Sistem Software pada Trainer
Hasil perancangan trainer ditunjukan pada gambar 7 :

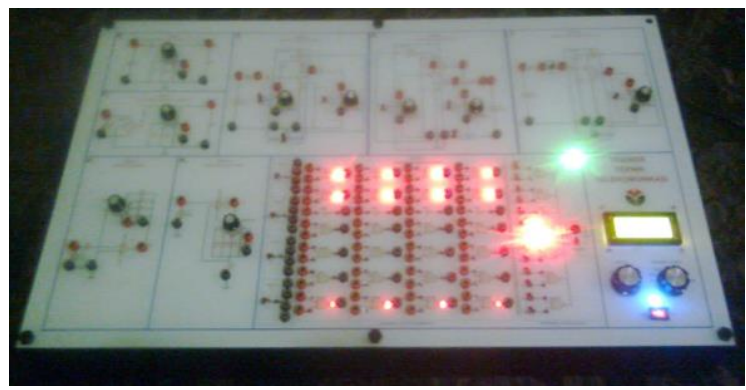

Gambar 7. Trainer Teknik Telekomunikasi

\section{SPESIFIKASI ALAT DAN TRAINER}

Perancangan trainer diharapkan dapat bekerja maksimal untuk Praktikum Teknik Telekomunikasi, dengan spesifikasi yang dirancang terlihat pada tabel 1 :

Tabel 1. Spesifikasi Alat Trainer Teknik Telekomunikasi

\begin{tabular}{|c|c|}
\hline Dimensi : & \\
\hline Panjang & $766,7 \mathrm{~mm}$ \\
\hline Lebar & $467,7 \mathrm{~mm}$ \\
\hline Tinggi (bagian atas) & $125 \mathrm{~mm}$ \\
\hline Tinggi (bagian bawah) & $75 \mathrm{~mm}$ \\
\hline Berat : & $7 \mathrm{~kg}$ \\
\hline Bahan Kotak & $\begin{array}{l}\text { Besi } 1 \mathrm{~mm} \\
\text { Akrilik } 3 \mathrm{~mm}\end{array}$ \\
\hline $\begin{array}{l}\text { Warna Kotak: } \\
\text { Tutup Atas } \\
\text { Alas Bawah } \\
\end{array}$ & $\begin{array}{l}\text { Putih } \\
\text { Hitam }\end{array}$ \\
\hline $\begin{array}{l}\text { Komponen-komponen } \\
\text { Teknis }\end{array}$ & $\begin{array}{l}\text { Transformator } 220 \quad \mathrm{~V} 3 \\
\text { A,DiodaBridge } \\
1 \text { A,Capasitor } 2200 \mathrm{uF}, \\
\text { IC Regulator } 7812,7912 \\
, 7805\end{array}$ \\
\hline Komponen Pasif & $\begin{array}{l}\text { Resistor, Potensiometer, } \\
\text { Capasitor, } \\
\text { Jumper, Buzzer, Relay }\end{array}$ \\
\hline Komponen Aktif & $\begin{array}{l}\text { Dioda in 4002, diode } \\
\text { bridge ,IC LM741, } \\
\text { Mikrokontroler } \\
\text { ATMEGA32 }\end{array}$ \\
\hline $\begin{array}{lr}\text { Modul 1 } & \text { Rangkaian } \\
\text { Penyearah } & \text { Setengah } \\
\text { Gelombang } & \end{array}$ & $\begin{array}{l}\text { Supply voltage : } 12 \text { volt AC } \\
\text { Diode : IN } 4002 \\
\text { Switch filter kapasitor } \\
\text { pilihan : } 0.47 \mathrm{uF}, 4.7 \mathrm{uF} \text {, } \\
100 \mathrm{uF} \\
\text { Input/output Banana flakes }\end{array}$ \\
\hline
\end{tabular}

Resa Pramudita, Ase Suryana 


\begin{tabular}{|c|c|}
\hline & $\begin{array}{l}2 \text { jack input } \\
2 \text { jack output } \\
\text { Switch rotary } \\
\text { Terintegrasi dengan } \\
\text { mikrokontroller modul } 1\end{array}$ \\
\hline $\begin{array}{lr}\text { Modul 2 } & \text { Rangkaian } \\
\text { Penyearah } & \text { Gelombang } \\
\text { Penuh } & \end{array}$ & $\begin{array}{l}\text { Supply voltage : } 12 \text { volt AC } \\
\text { Diode : IN } 4002 \text { terpasang } \\
\text { bridge } \\
\text { Switch filter kapasitor } \\
\text { pilihan : } 0.47 \mathrm{uF}, 4.7 \mathrm{uF} \text {, } \\
100 \mathrm{uF} \\
\text { Input/output Banana flakes } \\
2 \text { jack input } \\
2 \text { jack output } \\
\text { Switch rotary } \\
\text { Terintegrasi dengan } \\
\text { mikrokontroller modul } 2\end{array}$ \\
\hline $\begin{array}{l}\text { Modul } 6 \text { Rangkaian Op- } \\
\text { amp Inverting Amplifier }\end{array}$ & $\begin{array}{l}\text { Suply Voltage : } \pm 12 \text { Volt } \\
\text { (tegangan simetris) } \\
\text { IC Op-Amp LM } 741 \\
\text { Switch pilihan resistor Rf : } \\
10 \mathrm{~K}, 27 \mathrm{~K}, 82 \mathrm{~K}, 330 \mathrm{~K} \\
\text { Input/output Banana flakes } \\
2 \text { jack input } \\
2 \text { jack output } \\
\text { Switch rotary } \\
\text { Beda fasa } 180^{\circ} \\
\text { Terintegrasi dengan } \\
\text { mikrokontroller modul } 6\end{array}$ \\
\hline $\begin{array}{l}\text { Modul } 6 \text { Rangkaian Op- } \\
\text { amp non Inverting } \\
\text { Amplifier }\end{array}$ & $\begin{array}{l}\text { Suply Voltage : } \pm 12 \text { Volt } \\
\text { (tegangan simetris) } \\
\text { IC Op-Amp LM } 741 \\
\text { Switch pilihan resistor Rf : } \\
10 \mathrm{~K}, 27 \mathrm{~K}, 82 \mathrm{~K}, 330 \mathrm{~K} \\
\text { Input/output Banana flakes } \\
2 \text { jack input } \\
2 \text { jack output } \\
\text { Switch rotary } \\
\text { Beda fasa } 0^{5} \\
\text { Terintegrasi dengan } \\
\text { mikrokontroller modul } 7\end{array}$ \\
\hline
\end{tabular}

\section{ANALISIS DAN PERANCANGAN}

Pengujian alat dilakukan untuk menguji apakah trainer ini sudah berjalan dengan baik atau tidak. Pengujian dan hasil dari setiap modul adalah sebagai berikut:

\section{Pengujian Modul Penyearah Setengah Gelombang}

Pengujian Modul Rangkaian penyearah setengah gelombang dilakukan dengan membandingkan hasil pengujian praktikum dengan hasil simulasi Proteus (ideal) dan didapatkan hasil sebagai berikut :

Tabel 2. Perbandingan Hasil Pengujian Dengan Osiloskop Dan Simulasi,

Modul Penyearah Setengah Gelombang

\begin{tabular}{ccccc}
\hline No & $\begin{array}{c}\text { Nilai } \\
\text { capasitor }\end{array}$ & $\begin{array}{c}\text { U ripple Hasil } \\
\text { pengujian } \\
\text { software }\end{array}$ & $\begin{array}{c}\text { U ripple } \\
\text { Hasil } \\
\text { pengujian } \\
\text { osiloskop }\end{array}$ & Perbedaan \\
\hline $\mathbf{1 .}$ & $\mathbf{0 . 4 7} \mathbf{~ u F}$ & $12 \mathrm{vpp}$ & $14 \mathrm{vpp}$ & $2 \mathrm{Vp}-\mathrm{p}$ \\
$\mathbf{2 .}$ & $\mathbf{4 . 7} \mathbf{~ u F}$ & $6 \mathrm{vpp}$ & $4 \mathrm{vpp}$ & $2 \mathrm{Vp}-\mathrm{p}$ \\
$\mathbf{3 .}$ & $\mathbf{1 0 0} \mathbf{u F}$ & $0.8 \mathrm{vpp}$ & $0.28 \mathrm{vpp}$ & $0.52 \mathrm{Vpp}$ \\
\hline
\end{tabular}

Dari hasil diatas dapat disimpulkan bahwa semakin besar nilai kapasitor maka semakin kecil nilai tegangan ripplenya. Dan menyatakan bahwa hasil pengujian trainer ini sudah mendekati hasil pengujian yang ideal sehingga Modul Rangkaian penyearah setengah gelombang dapat digunakan sebagai modul praktikum.

2. Pengujian Modul Rangkaian Penyearah Gelombang Penuh

Pengujian Modul Rangkaian penyearah gelombang penuh dilakukan dengan membandingkan hasil pengujian praktikum dengan hasil simulasi Proteus (ideal) dan didapatkan hasil sebagai berikut:

Tabel 3. Perbandingan Hasil Pengujian Dengan Osiloskop Dan Simulasi

Modul penyearah setengah gelombang

\begin{tabular}{ccccc}
\hline No & $\begin{array}{c}\text { Nilai } \\
\text { capasitor }\end{array}$ & $\begin{array}{c}\text { U ripple Hasil } \\
\text { pengujian } \\
\text { software }\end{array}$ & $\begin{array}{c}\text { U ripple } \\
\text { Hasil } \\
\text { pengujian } \\
\text { osiloskop }\end{array}$ & Perbedaan \\
\hline $\mathbf{1 .}$ & $\mathbf{0 . 4 7} \mathbf{~ u F}$ & $10 \mathrm{vpp}$ & $12 \mathrm{vpp}$ & $2 \mathrm{Vpp}$ \\
$\mathbf{2 .}$ & $\mathbf{4 . 7} \mathbf{~ u F}$ & $5 \mathrm{vpp}$ & $4 \mathrm{vpp}$ & $1 \mathrm{Vpp}$ \\
$\mathbf{3 .}$ & $\mathbf{1 0 0} \mathbf{u F}$ & $1 \mathrm{vpp}$ & $1.1 \mathrm{vpp}$ & $0.1 \mathrm{Vpp}$ \\
\hline
\end{tabular}

Dari hasil diatas dapat disimpulkan bahwa semakin besar nilai kapasitor maka semakin kecil nilai tegangan ripplenya. Dan menyatakan bahwa hasil pengujian trainer ini sudah mendekati hasil pengujian yang ideal sehingga Modul Rangkaian penyearah gelombang penuh dapat digunakan sebagai modul praktikum.

\section{Pengujian Modul Rangkaian Penguat Inverting}

Pengujian Modul Rangkaian Penguat Inverting dilakukan dengan membandingkan hasil pengujian

Resa Pramudita, Ase Suryana 
praktikum dengan hasil simulasi Proteus (ideal) dan didapatkan hasil sebagai berikut:

Tabel 4. perbandingan hasil pengujian dengan osiloskop dan simulasi

Modul 6 penguat inverting

\begin{tabular}{|c|c|c|c|c|c|c|c|c|}
\hline No & $\begin{array}{c}\text { Nilia } \\
\text { resistor } \\
\mathbb{R f}\end{array}$ & $\begin{array}{c}\text { Nilai } \\
\text { Resistor } \\
\text { input }\end{array}$ & $V$ input & $\begin{array}{c}\text { Nilai output } \\
\text { Hasil penguaijan } \\
\text { software }\end{array}$ & $\begin{array}{c}\text { Penguatan } \\
\text { Perbitumagan } \\
\text { Software }\end{array}$ & $\begin{array}{c}\text { Nilai output } \\
\text { Hasil } \\
\text { pengugijan } \\
\text { psilstion }\end{array}$ & $\begin{array}{c}\text { Renguatan } \\
\text { perhitungan } \\
\text { Osilloskop. }\end{array}$ & $\begin{array}{c}\text { Beda } \\
\text { Dhasa } \\
(\varphi)\end{array}$ \\
\hline 1. & $10 \mathrm{~K}$ & $10 \mathrm{~K}$ & $100 \mathrm{mVlog}$ & 100 maxzR & 1 kali & 100 guxgr & 1 kali & $180^{\circ}$ \\
\hline 2. & $27 \mathrm{~K}$ & $10 \mathrm{~K}$ & $100 \mathrm{mVpr}$ & 270 maxbR & $2.7 \mathrm{kali}$ & 270 mugR & 2.7 kali & $180^{\circ}$ \\
\hline 3. & $82 \mathrm{~K}$ & $10 \mathrm{~K}$ & $100 \mathrm{mVpg}$ & 820 maxp & $8.2 \mathrm{kali}$ & 800 mugre & $8 \mathrm{kali}$ & $180^{\circ}$ \\
\hline 4. & $330 \mathrm{~K}$ & $10 \mathrm{~K}$ & $100 \mathrm{mVgp}$ & 3.3 volt & 33 kali & 3.2 volt & $320 \mathrm{kali}$ & $180^{\circ}$ \\
\hline
\end{tabular}

Dari tabel di atas dapat diambil kesimpulan bahwa semakin besar nilai resistor rf (resistor pembagi) maka semakin besar penguatannya dan beda phasanya adalah $180^{\circ}$.hasil pengujian trainer ini sudah mendekati hasil pengujian yang ideal sehingga Modul Rangkaian Penguat Inverting dapat digunakan sebagai modul praktikum.

4. Pengujian Modul Rangkaian Penguaty non inverting

Pengujian Modul Rangkaian Penguat Non Inverting dilakukan dengan membandingkan hasil pengujian praktikum dengan hasil simulasi Proteus (ideal) dan didapatkan hasil sebagai berikut:

Tabel 5. Perbandingan Hasil Pengujian Dengan Osiloskop Dan Simulasi

Modul Penguat Non Inverting

\begin{tabular}{|c|c|c|c|c|c|c|c|c|}
\hline No & $\begin{array}{c}\text { Nilai } \\
\text { resistor } \\
\text { Rf }\end{array}$ & $\begin{array}{l}\text { Nilai } \\
\text { resistor } \\
\text { input }\end{array}$ & $\underset{\text { input }}{\mathbf{v}}$ & $\begin{array}{c}\text { Nilai } \\
\text { output } \\
\text { Hasil } \\
\text { pengujian } \\
\text { software }\end{array}$ & $\begin{array}{c}\text { Penguatan } \\
\text { Perhitungan } \\
\text { Software }\end{array}$ & $\begin{array}{c}\text { Nilai output } \\
\text { Hasil } \\
\text { pengujian } \\
\text { esiloskop. }\end{array}$ & $\begin{array}{c}\text { Penguatan } \\
\text { Perhitungan } \\
\text { Qsiloskop. }\end{array}$ & $\begin{array}{r}\text { Beda } \\
\text { phasa } \\
(\varphi)\end{array}$ \\
\hline 1. & $10 \mathrm{~K}$ & $10 \mathrm{~K}$ & $\begin{array}{c}100 \\
\text { mVpp }\end{array}$ & 200 mxpR & 2 kali & 200 mXRR & 2 kali & $0^{\circ}$ \\
\hline 2. & $27 \mathrm{~K}$ & $10 \mathrm{~K}$ & $\begin{array}{c}100 \\
\mathrm{mXpp}\end{array}$ & 370 mXNpR. & $3.7 \mathrm{kali}$ & 380 mXpp. & $3.8 \mathrm{kali}$ & $0^{\circ}$ \\
\hline 3. & $82 \mathrm{~K}$ & $10 \mathrm{~K}$ & $\begin{array}{c}100 \\
\text { mVpp }\end{array}$ & 920 mxRR & $9.2 \mathrm{kali}$ & 960 mXxp & $9.6 \mathrm{kali}$ & $0^{\circ}$ \\
\hline 4. & $330 \mathrm{~K}$ & $10 \mathrm{~K}$ & $\begin{array}{c}100 \\
\mathrm{mV} p\end{array}$ & 3.4 volt & 34 kali & 3.6 volt & $36 \mathrm{kali}$ & $0^{\circ}$ \\
\hline
\end{tabular}

Dari tabel di atas dapat diambil kesimpulan bahwa semakin besar nilai resistor rf (resistor pembagi) maka semakin besar penguatannya dan beda phasanya adalah $0^{\circ}$.hasil pengujian trainer ini sudah mendekati hasil pengujian yang ideal sehingga Modul Rangkaian Penguat Inverting dapat digunakan sebagai modul praktikum.

\section{KESIMPULAN DAN SARAN}

Berdasarkan hasil pengujian trainer, maka dapat disimpulkan trainer ini sebagian besar sudah dapat berjalan dengan baik sebagai media pembelajaran Trainer Teknik Telekomunikasi. Pada trainer ini masih terdapat perbedaan pengukuran yang belum sesuai dengan teori menurut hasil ideal. Hal ini diperkirakan karena masalah keakurasian dalam pembacaan alat ukur (kesalahan parallax), namun masih dalam tahap toleransi. Untuk meningkatkan kinerja trainer maka penggunaan komponen yang ideal lebih dititikberatkan agar trainer dapat bekerja dengan maksimal.

\section{REFERENSI}

Arsada, Robbi. (2012). SolidWorks Professional 2012. Bandung: Informatika.

Indriyanto (2012) : PENGEMBANGAN MEDIA PEMBELAJARAN DASAR OPERASIONAL AMPLIFIER (OP-AMP) BERBASIS FLASH UNTUK SEKOLAH MENENGAH KEJURUAN (SMK) ,jurnal elektronik pendidikan teknik elektronika vol 1 , no 2

\section{Rahayu (2012) : MEDIA PEMBELAJARAN TRAINER ELEKTRONIKA DASAR UNTUK MATA PELAJARAN ELEKTRONIKA DASAR , jurnal ilmiah Universitas Negeri Yogyakarta}

Rangkuti, Syahban. (2011). Mikrokontroller ATMEL AVR. Bandung: Informatika.

Universitas Pendidikan Indonesia. (2011). Pedoman Penulisan Karya Ilmiah. Bandung: UPI.

Modul Diklat Elektronika dasar universitas negeri jember (ONLINE), tersedia di : http://kambing.ui.ac.id/onnopurbo/oraridiklat/teknik/elektronika/elektronika-dasar-Iuniv-negeri-jember/bab08-rangkaianpenyearah.pdf

Iswanto, Modul Kuliah Elektronika, Universitas Muhammadiyah Yogyakarta (ONLINE), tersedia di :

http://iswanto.staff.umy.ac.id/files/2012/0

6/BAB-5-V.doc

Resa Pramudita, Ase Suryana 